\title{
PODER CONSTITUINTE ORIGINÁRIO E SEUS LIMITES JURÍDICOS
}

\author{
Olavo Augusto Vianna Alves Ferreira ${ }^{1}$ \\ Maiara Sanches Machado Rocha ${ }^{2}$
}

\begin{abstract}
RESUMO: O presente trabalho visa demonstrar a origem do Poder Constituinte, a importância deste diploma legal para o surgimento de um ordenamento jurídico, iniciando uma ordem jurídico-política-social ou estabelecendo uma ruptura absoluta com as normas anteriores, criando uma nova Constituição. Objetiva-se demonstrar as características deste instituto, se há ou não limitações, e se este é um poder soberano, não havendo qualquer direito ou norma que o restrinja. Para explanação abordaremos as teses positivistas e jusnaturalistas ao tratarmos da soberania (ou não) do Poder Constituinte Originário.
\end{abstract}

Palavras-chave: Poder Constituinte Originário; Limites; Soberania; Constituição.

\section{THE ORIGINAL CONSTITUENT POWER AND ITS LEGAL BOUNDARIES}

\begin{abstract}
This study aims to demonstrate the origin of the constituent power, the importance of this legal instrument for the emergence of a legal system, starting a legalpolitical-social order or setting an absolute break with previous standards, creating a new constitution. It aims to demonstrate the features of this institute, whether or not limitations, and this is a sovereign power, there is no law or regulation that restricts. For a discussion discuss the positivist and natural law theories of sovereignty to treat (or not) of the Constituent Power Originating.
\end{abstract}

Keywords: Constituent Power Originating; Limit; Sovereignty; Constitution

\footnotetext{
${ }^{1}$ Procurador do Estado de São Paulo, Doutor e Mestre em Direito do Estado pela PUC-SP (Sub-área Direito Constitucional), Professor do Programa de Mestrado em Direito da UNAERP e professor convidado de cursos de pós-graduação (PUC-COGEAE, UFBA, Faculdade Baiana de Direito, JUSPODIVM, e USP-FDRP), orientador da pós-graduação da Escola Superior da Procuradoria Geral do Estado de São Paulo e da pós-graduação de Processo Civil da USP-FDRP.

${ }^{2}$ Oficial de Registros no Estado de Sergipe, Mestranda em Direito - Proteção e Tutela dos Direitos ColetivosUniversidade de Ribeirão Preto/SP, Doutoranda em Direito - Ciências Jurídicas - Pontificia Universidad Católica Argentina.
} 
INTRODUÇÃO

A sociedade vem sofrendo diversas e profundas mudanças no decorrer dos tempos, originadas de acontecimentos históricos e devido a evolução do indivíduo e a busca pela efetivação dos direitos.

O objetivo principal do presente artigo é buscar conhecimentos para responder ao seguinte questionamento: O Poder Constituinte Originário é soberano? Há em nosso ordenamento uma norma que ofereça limitações a este poder?

Abordar-se-á para tanto, os limites decorrentes de matéria de direito interno, não tratando a respeito de limitações impostas por Tratados e Convenções Internacionais sobre direitos humanos, nem a questão das limitações de fato.

Em um primeiro momento cabe tratar a respeito do histórico do Poder Constituinte Originário, como este poderá se manifestar frente a um Estado e a um ordenamento jurídico. Em segundo, abordar-se-á a respeito das escolas positivistas e jusnaturalistas e as limitações ao Poder Constituinte Originário.

O objetivo principal do presente estudo é demonstrar se há ausência de limites na atuação desse poder inovador, o qual abre caminho para diversas mudanças. Para tanto utilizarse-á de pesquisas bibliográficas e do método dedutivo.

O estudo visa a compreensão de um poder constituinte criador de uma ordem jurídica, porém sendo a ele antecede uma ordem natural. Diante da ruptura causada pelo poder respeitar-se-á uma ordem anteriormente constituída, a qual não poderá ser abolida.

Em busca das respostas apresentar-se-á o histórico do Poder Constituinte Originário, seu conceito, passando ao estudo do positivismo e das características dadas por essa corrente ao poder. Posteriormente tratar-se-á do jusnaturalismo, abrangendo o Direito Natural e a limitação imposta por esse a manifestação do Poder Constituinte. Por fim, abordaremos a questão central do nosso estudo, qual seja, a existência ou não de limites à atividade do Poder Constituinte.

\section{PODER CONSTITUINTE ORIGINÁRIO}

Ao falarmos de sociedade intrinsecamente ligada a ela temos o direito visto que uma sociedade não é composta sem um conjunto de normas que estabeleçam suas diretrizes. A 
partir desta concepção, indaga-se: a quem é dado o poder de estruturar uma sociedade? Estabelecer suas normas jurídicas, seu ordenamento, diretrizes e princípios?

Diante de tais indagações a resposta cabível é: cabe ao Poder Constituinte Originário o poder-dever de constituir uma sociedade, posto que a própria expressão constituinte deriva da palavra constituir, ou seja, faz parte da essência deste poder a criação de uma nova ordem jurídica. Questiona-se: “Quem é o terceiro Estado?”3.

\subsection{Histórico}

Iniciaremos o presente trabalho a partir da caracterização do Poder Constituinte Originário em um momento de ruptura. Essa associação decorre posto que este poder tem a força de romper com qualquer ordem jurídica pré-existente. Por meio desta força é capaz de se criar a partir de um vazio uma nova ordem jurídica, social e política, sendo, portanto, o responsável pelo primeiro e mais importante diploma legal de um ordenamento jurídico. Tratase da base, do pilar que fundamenta a validade de todos os atos normativos do Estado.

O Poder Constituinte Originário poderá ocorre de duas formas: (a) a primeira denominada de histórica, posto que se trata da primeira Constituição de um Estado, fundandose aquela comunidade política; (b) a segunda maneira ocorre no momento de ruptura de uma ordem jurídica anteriormente instalada, a qual não mais terá qualquer ligação com a nova Constituição, ou seja, trata-se de uma ruptura completa.

Trataremos da teoria clássica, explicando seus conceitos e características e, mais importante, é demonstrar que a teoria utilizada em busca de um liberalismo e democracia pode por vezes se aplicada de maneira autoritária ou mesmo antiliberal. O que temos quando da aplicação da teoria clássica autoritariamente é que o poder se equipara a lei.

Primeiramente, ante ao desenvolvimento da teoria temos de acordo com Ferreira Filho (2007, p. 08), o desenvolvimento do conceito de nação por Sieyès, o qual é diretamente influenciado pelos pensamentos de Rosseau. Verifica-se uma diferença entre ambos os pensadores posto que para Rosseau a participação do povo deve ser direta, realizada pelos

\footnotetext{
${ }^{3}$ Escrito no original: Qu'est-ce que le tiers État.? Tal obra consiste no verdadeiro manifesto da Revolução Francesa, ode expõe as reivindicações da burguesia, definindo-a como a nação e, conseqüentemente, titular do Poder Constituinte. Hoje predomina na doutrina o entendimento que o povo é titular do Poder Constituinte, neste sentido: Manoel Gonçalves Ferreira Filho, O poder constituinte, p. 158; e Michel Temer, Elementos de Direito Constitucional, p. 32.
} 
próprios cidadãos e opondo-se a este pensamento, tem-se Sieyès sendo este a favor da democracia representativa entendendo que a vontade política somente ocorre por meio de representantes da nação.

Sieyès criara um novo conceito jurídico, o do Poder Constituinte, colocando a nação como titular do poder, identificando como base de um elemento da democracia o poder dado aos membros da comunidade política para a criação de Constituição (LISOWSKI, 2013, p. 20).

Importante frisar o momento inicial do pensamento de Sieyès uma vez que este ocorrera na divulgação de panfletos criados por Emmanuel Sieyès diante a Revolução Francesa, nos quais o questionamento era: "O que é o terceiro Estado"? Expondo brevemente, informamos que à época os votos nos Estados Gerais eram contados mediante o privilégio dos estamentos, ou seja, a nobreza e clero, apesar de representar menos de $5 \%$ da população francesa era possível que estes negassem qualquer pedido. Diante de toda essa situação a burguesia, posteriormente, se autoproclamou Assembleia Nacional, se autodenominando representantes legítimos do povo e da nação, se tratando do golpe de Estado do 17 de julho (PASQUINO, 1998, p. 115).

Diante do gole, enfraqueceu-se os feudos e os privilégios foram extintos. A Revolução Francesa objetivando a busca da igualdade jurídico-formal, com fundamento anterior da ordem normativa, social e jurídica no Deus que transcendia a tudo e todos, modifica sua base, colocando em seu lugar, nos dizeres de Sieyès, a nação. Ressalta-se que para este pensador o titular do poder é a nação, não se confundindo este conceito com povo (SIEYÈS, 1973, p. 12).

O questionado anteriormente, de autoria de Sieyès (1973, p. 13), é respondido pelo mesmo de maneira direta sendo o Terceiro Estado "um corpo de associado que vivem sob uma lei comum e são representados pela mesma legislatura".

Nos pensamentos de Sieyès (1973, p. 13-14), o principal ponto do conceito exposto acima está ao dizer que todos vivem sob uma lei comum, portanto, não teria mais a nobreza o privilégio que a esta classe antes era conferida, sendo assim para aquele se os nobres possuíam privilégios, direitos separados dos demais, saindo da lei comum, não faziam dos nobres uma parte da nação.

Nos ensinamentos de Ferreira Filho (2007, p. 23), importante frisar que a nação de Sieyès na Revolução Francesa não abrangia a nobreza, porém este conceito venceu as barreiras do tempo e espeço, sendo contínuo e permanente, sendo nos dizeres do autor "povo, para ele, é o conjunto dos indivíduos, é um mero coletivo, uma reunião de indivíduos que estão sujeitos a 
um poder. Ao passo que nação é mais do que isso, porque nação é a encarnação de uma comunidade em sua permanência [...]".

Ponto importante a ressaltar e que trouxe um grande sucesso a teoria é a distinção trazida por Sieyès no que tange ao Poder Constituinte e Poderes Constituídos, posto que para o pensador Poder Constituinte é a origem de todo poder, uma vez que ele não é criado e sim o criador de toda uma nova ordem jurídica e responsável pela delimitação de poderes que sejam posteriores a ele (poderes constituídos) (FERREIRA FILHO, 2007, p. 35).

A leitura da obra "O que é o Terceiro Estado" nos faz concluir que o Poder Constituinte não é um poder constituído não derivando de qualquer outro ordenamento jurídico, sua origem é reconhecida em um momento de ruptura, do qual o poder faz nascer de um vazio absoluto uma nova ordem jurídica no Estado, ou faz nascer um Estado, por meio de uma Constituição.

Na obra Teoria de la Constituición, Carl Shmmit (2003, p. 93-94) escreve o quanto segue a respeito do Poder Constituinte:

Poder constituyente es la voluntad política cuya fuerza o autoridade es capaz de
adoptar la concreta decisión de conjunto sobre modo y forma de la propia existência
política, determinando así la existência de la unidad política como um todo. De las
decisiones de esta voluntad se deriva la validez de toda ulterior regulación legal-
constitucional. Las decisiones, como mías, son cualitativamente distintas de las
normaciones legal-constitucionales estabelecidas sobre su base.
Uma Constituición no se apoya em uma norma cuya justicia sea fundamento de su
validez. Se apoya em uma decisión política surgida de um Ser político, acerca del
modo y forma del próprio Ser. ${ }^{4}$

Demonstrado o surgimento da teoria do poder constituinte, algumas características, definido o conceito de nação por Sieyès, pensador que deu origem a esse instituto, passaremos a discorrer o real conceito do Poder Constituinte Originário e posteriormente se este encontra limitações postas pelo direito ou se é de um poder ilimitado, incondicionado e onipresente.

\footnotetext{
${ }^{4}$ Poder constituinte é a vontade política ou autoridade cuja força é capaz de tomar uma decisão concreta sobre modo e forma da própria existência política, determinando assim a existência de uma unidade política como um todo. Das decisões de vontade se deriva a validade de toda regulação ulterior jurídico-constitucional. As decisões, como minhas, são qualitativamente distintas das normas jurídico-constitucionais estabelecidas sobre sua base. Uma Constituição não se apoia em uma norma cuja justiça seja o fundamento de sua validade. Se apoia numa decisão política surgida de Ser político, acerca do modo e forma do próprio Ser. (tradução livre)
}

Rev. Brasileira de Teoria Constitucional | e-ISSN: 2525-961X | Maranhão | v. 3 | n. 2 | p. 78 - 93 | Jul/Dez. 2017 


\subsection{Conceito}

Ao se pensar em sociedade pensamos em direito, porém deve-se indagar o surgimento deste direito, como este fora posto a ser obedecido e respeitado por cada indivíduo, por meio de qual sistema houve a criação e estabelecimento de regras a serem cumpridas? Nas lições de Michel Temer (2002, p. 32) "ao se aludir à sociedade, pode-se indagar quem é que tem o poder de estruturá-la, dar-lhe corpo, constituí-a”.

O Poder Constituinte para Schmmit (2003, p. 94) manifesta sua força decidindo a forma de existir do Estado, a criação deste a partir de um vazio, decidindo suas bases, fundamentos e estrutura. Por conseguinte, é um produto de decisão política. Nos dizeres do autor, a Constituição, norma fundamental, encontra seu fundamento de validade em uma decisão política antecedente a ela, não apoiando a validade de suas normas na justiça, conforme anteriormente exposto.

O Poder Constituinte implica em uma ruptura da ordem jurídica vigente até aquele momento. Trata-se de um poder revolucionário, podendo ser denominado de poder instituidor, genuíno ou de primeiro grau. Nos moldes dos ensinamentos de Celso Ribeiro Bastos (1994, p. 57) "consiste na quebra da sequência da ordem jurídica anterior, seja pela alteração do seu conteúdo, seja pela deslocação da fonte de sua legitimidade".

Diante da manifestação do Poder Constituinte ao criar uma nova Constituição, há o nascimento de um novo Estado, mesmo que perante a mesma sociedade, o momento é de ruptura. Pode-se dizer que historicamente e geograficamente o Estado continua a ser o mesmo, porém não mais o é juridicamente. Michel Temer (2002, p. 33) aduz que "antes da manifestação, o Estado, tal como veio positivado, não existia. Existe é, a partir da Constituição $[\ldots] "$.

Schmitt afirma surgimento de uma Constituição trata-se de uma "vontade política cuja força ou autoridade é capaz de adotar a concreta decisão de conjunto sobre modo e forma da própria existência política, determinando assim a existência da unidade política como um todo" (SCHIMITT, 2003, p. 93-94).

De acordo com Ribeiro Lopes (1999, p. 46) “a concepção de Sieyès prende ao Estado a ideia de que ao mesmo é indispensável uma Constituição e que esta é obra de um poder anterior a ela própria- o Poder Constituinte" 5 .

\footnotetext{
5 RIBEIRO LOPES, Maurício A. Poder Constituinte Reformador: limites e possibilidades da revisão constitucional brasileira, p. 46
}

Rev. Brasileira de Teoria Constitucional | e-ISSN: 2525-961X | Maranhão | v. 3 | n. 2 | p. 78 - 93 | Jul/Dez. 2017 
"É a manifestação soberana da vontade de um ou alguns indivíduos capazes de fazer nascer um núcleo social” (TEMER, 2002, p. 29) e conforme a própria caracterização do nome é um poder que "visa constituir, criar, positivar, normas jurídicas de valor constitucional" (FERREIRA FILHO, 2001, p. 21).

Manoel Gonçalves (2001, p. 21) entende que a ideia de Poder Constituinte é contemporânea a ideia de uma constituição escrita, neste sentido afirma:

\begin{abstract}
A idéia de que a constituição é fruto de um poder distinto dos que estabelece, a afirmação da existência de um Poder constituinte, fonte da constituição e, portanto, dos poderes constituídos (dentre os quais o legislativo) é contemporânea da de constituição escrita.
\end{abstract}

Imperioso salientar importante dizeres de Paulo Bonavides (2000, p. 120) a respeito do presente tema posto que este faz menção a diferença entre o Poder Constituinte, já existente na sociedade desde tempos remotos e a teorização deste poder, a qual ocorrera em meados do século XVIII:

Cumpre, todavia não confundir o poder constituinte com a sua teoria. Poder constituinte sempre houve em toda sociedade política. Uma teorização desse poder para legitimá-lo, numa de suas formas ou variantes, só veio a existir desde o século XVIII, por obra da sua reflexão iluminista, da filosofia do contrato social, do pensamento mecanicista anti-historicista e anti-autoritário do racionalismo francês, com sua concepção de sociedade.

Alguns doutrinadores, como Bidart Campos (1969, p. 161-162), entendem o Poder Constituinte como uma competência ou capacidade para cumprir um fim, em seus dizeres:

Se por 'poder' entendemos uma competência, capacidade ou energia para cumprir um fim, e por 'constituinte' o poder que constitui ou dá constituição ao estado, alcançamos com bastante precisão o conceito global: poder constituinte é a competência, capacidade ou energia para constituir ou dar constituição ao estado, é dizer, para organizá-lo.

Importante ainda abordar a respeito da titularidade do Poder Constituinte com o intuito de buscar "saber a que entidade política compete a faculdade de dar à nação a Constituição" (SALDANHA, 1986, p.73).

O entendimento de Paulo Bonavides (1998, p. 128) é que o poder constituinte, em sentido político, somente teria uma "função de capital: a de fazer que a Nação ou o Povo, os 
governados enfim, sejam os sujeitos da soberania". Para o autor não importa se é a nação ou o povo o titular do poder e sim que estes sejam os sujeitos do Estado.

Diferentemente do conceito exposto por Seiyès uma vez que este ser a nação a titular do poder constituinte, o conceito de povo seria um conjunto de indivíduos ligados por uma cultura ou etnia, porém não unidos por um objetivo político (LISOWSKI, 2013, p. 20).

Observa-se que a titularidade do povo será exercida por meio da representação, pois de fato, esta ideia está intimamente ligada ao conceito de representação (FERRAZ JÚNIOR, 1985, P. 24).

Jorge Miranda (2007, p. 49), a respeito da representação política alega:

Cuida-se, sim, de representação do povo enquanto modo de tornar o povo (ou o conjunto dos governados) presente no exercício do poder através de quem ele escolha ou de quem tenha a sua confiança. A representação política é o modo de o povo, titular do poder, agir ou reagir relativamente aos governantes.

Vale ressaltar neste ponto que Rousseau (2003, p. 91), importante teórico da soberania popular, não defende a ideia de representação do povo, posto que para o pensador “não se pode representar a soberania pela mesma razão que não pode alienar; consiste ela essencialmente na vontade geral, e a vontade não se representa; ou ela é a mesma, ou outra, e nisso não há meio termo". Portanto, para Rousseau a soberania somente é exercida quando diretamente feita pelo povo.

Na sociedade contemporânea entende-se que predomina o pensamento de que o titular do "supremo poder, num Estado, pertence ao povo; a soberania é do povo; portanto, o Poder Constituinte é do povo" (FERREIRA FILHO, 1999, p. 30).

Por todo exposto, caracteriza-se o Poder Constituinte como poder de elaborar a base jurídica de um Estado, fazendo-o surgir quando não existente, ou provendo um novo Estado, criando a Lei Fundamental, atribuindo-lhe validade e constituindo o marco inicial do ordenamento jurídico, sendo o povo titular deste poder.

No que tange a limitação do Poder Constituinte passaremos a abordar as teorias positiva e jusnaturalista buscando demonstrar se se este poder encontra limites no direito. 


\section{POSTIVISMO VERSUS JUSNATURALISMO}

\subsection{POSITIVISMO E O PODER JURIDICAMENTE ILIMITADO}

O pensamento da escola positivista se fundamenta na ideia de que todo o direito se resume em um direito positivo, isto é, um direito posto, manifestado na lei, em normas jurídicas, determinado pelo Estado.

O positivismo rompeu as concepções tradicionais do direito, passando a ser um direito decorrente de uma construção humana e imposto por uma autoridade. Esta imposição poderia ocorrer por meio de textos legais ou não. Passou então a ser considerado um direito pré-posto ou imposto (BRONZE, 2002, p. 282).

Como salienta Castanheira Neves (1995, p. 284), o direito precedente ao positivismo partia da prática e de reflexões buscando-se o justo. Para esse direito, sua base vai além do que fora imposto, tendo como exemplo de fundamento uma "ordem" que rege a sociedade.

Em contraponto, com a sedimentação do direito positivo, passa-se a ter um direito autônomo, o qual impõe as mesmas ordens, porém em caráter obrigatório. Sendo assim, o pensamento jurídico passa a ser uma condição de objeto do direito agora posto por uma autoridade. Ressalta-se que o direito anterior versava com base em uma filosofia prática (NEVES, 1995, p. 284).

O positivismo deve ser conceituado como uma posição filosófica que busca a sua causa última nas relações entre os fatos observáveis. Como método, subordina-se à observação dos fenômenos, ao procurar na ciência o conhecimento verdadeiro, de maneira que sejam abstraídos os conhecimentos ligados às crenças ou outras práticas não verificáveis cientificamente. [...]

A ciência é, para essa corrente filosófica, a única base da vida em sociedade e garantia absoluta do progresso humano. A fé na racionalidade científica para os problemas sociais distancia-a de pressupostos teológicos e metafísicos. (MONTEIRO, 2010)

No que tange ao positivismo jurídico, decorrente do positivismo lógico, anteriormente exposto, Ott (1992, p. 111) expõe que todo direito é positivo e emana do poder do Estado. Para Monteiro (2010) o direito positivo é coercitivo:

O direito positivo é essencialmente uma ordem de coerção; suas regras derivam da vontade arbitraria de uma autoridade humana e, por esse motivo, simplesmente por causa da natureza de sua origem, essas regras não podem ter a qualidade da autoevidência imediata.

Rev. Brasileira de Teoria Constitucional | e-ISSN: 2525-961X | Maranhão | v. 3 | n. 2 | p. 78 - 93 | Jul/Dez. 2017 
A arbitrariedade humana imposta por meio de lei escrita é exteriorizada na Constituição de um Estado, promulgada por um Poder Constituinte Originário, o qual rege as normas de toda uma sociedade.

Sendo assim, para a corrente positivista o fundamento das leis é embasado em uma Constituição, portanto, para uma lei ser considerada válida deverá haver compatibilidade com o texto constitucional posto ao Estado pelo Poder Constituinte Originário. Aos que aderem à corrente positivista há que ressaltar que "a Constituição deve ser obedecida" (MODESTO, 1999, p. 101), sejam suas normas justas ou não.

Relativamente ao Poder Constituinte Originário, na visão da corrente positivista, este é caracterizado como um poder ilimitado uma vez que por ser um poder que causa ruptura com a ordem jurídica anterior, não há que se falar em invocação de normas para restringir sua atuação.

Importante expor as peculiaridades do Poder Constituinte Originário trazidas por Canotilho (1993, p.94), o qual evidencia ser aquele "um poder onipotente, incondicionado: o poder constituinte não está subordinado a qualquer regra de forma ou de fundo".

Outrossim, para os positivistas o Poder Constituinte Originário faz surgir um novo Estado e consequentemente uma nova ordem jurídica, totalmente desvinculada da ordem precedente, portanto, não há limitação em decorrência da não existência de normas anteriores que as instituam.

O surgimento do direito decorre do surgimento da Constituição a qual somente nascerá diante da manifestação do Poder Constituinte, o qual fundamentará a validade das regras jurídicas que vieram a ser criadas.

Os atos praticados pelo Poder Constituinte Originário não são passíveis de alegação de inconstitucionalidade posto ao seu caráter de poder "ilimitado", ou seja, não que se alegar a compatibilidade ou incompatibilidade com outros diplomas pátrios.

Neste ponto cabe ressaltar que o Supremo Tribunal Federal adotou a teoria positivista ao inadmitir a tese de inconstitucionalidade de normas constitucionais, logo, "a tese de que há hierarquia entre normas constitucionais originárias dando asa à declaração de inconstitucionalidade de umas em face de outras é incompatível com o sistema de Constituição rígida" $\left(\mathrm{ADIN} \mathrm{n}^{\mathrm{o}} 815-3\right)^{6}$.

\footnotetext{
${ }^{6}$ STF - Pleno - Adin nº 815-3, Rel. Min. Moreira Alves, Diário da Justiça, Seção I, 10 de maio de 1996, p. 15.131
}

Rev. Brasileira de Teoria Constitucional | e-ISSN: 2525-961X | Maranhão | v. 3 | n. 2 | p. 78 - 93 | Jul/Dez. 2017 
Ao não se admitir a inconstitucionalidade de normas constitucionais enfatiza-se o poder ilimitado do Poder Constituinte Originário, sendo o livre exercício da criação de um novo ordenamento. Nos ensinamentos de Ferreira Filho (2007, p. 71):

Dentro de uma perspectiva positivista, o Poder Constituinte é juridicamente ilimitado, por uma razão óbvia, porque, para a doutrina positivista, não há direito antes da manifestação do Poder Constituinte, portanto, não há direito que possa ser invocado contra o Poder Constituinte.

Por todo exposto, a corrente positivista adota um caráter ilimitado ao Poder Constituinte Originário, não há normas anteriores que limitem a atuação e o exercício deste poder para fazer surgir uma nova Constituição, um novo Estado.

\subsection{JUSNATURALISMO E A LIMITAÇÃO DO PODER CONSTITUINTE ORIGINÁRIO}

Primeiramente, há que ressaltar que o jusnaturalismo está ligado ao Direito Natural porém ambos não se confundem. Jusnaturalismo trata-se de uma teoria a qual defende e fundamenta o Direito Natural e sua soberania frente ao Direito Positivo (PEREZ LUÑO, 1971, p. 33). Importante salientar que o Direito Natural é constituído por uma ordem de princípio eternos, absolutos e imutáveis (PEREZ LUÑO, 1971, p. 37).

De acordo com o jusnaturalismo, o direito antecede ao homem. Para Ferreira Filho (2007, p. 51) “esse direito é, grosso modo, o que resulta da natureza humana. É o chamado direito natural".

Várias são as escolas que tratam a respeito do jusnaturalismo, porém o presente estudo abordará somente duas, sendo elas a Escola Tomista e a Escola do Direito Natural e das Gentes.

A Escola Tomista defende que o:

[...]direito eterno, a Lei Eterna, que é a própria Razão Divina, é a própria razão de Deus. Dessa Lei Eterna, o homem conhece uma parcela, através da Revelação ou da Igreja. Mas, por uma inclinação de sua razão, o homem tem acesso a uma outra parcela da Lei Eterna, e que é exatamente a Lei Natural. (FERREIRA FILHO, 2007, p. 51) 
Nos ensinamentos da Escola Tomista, as leis devem ser obedecidas pelo homem e essas provêm de um ser superior, um ser Divino. A lei positiva não é negada pela escola, porém esta somente deverá ser observada quando em consonância com a Lei Eterna.

Portanto, a Escola Tomista defende que o poder emana de Deus, as leis e os fundamentos devem ser baseados na Lei Divina.

Em contrapartida, a Escola do Direito Natural e das Gentes influenciara "contrato social e, portanto, no pensamento iluminista que, no século XVIII, prevaleceu e se refletiu nas revoluções desse século" (FERREIRA FILHO, 2007, p. 52).

Cabe a explicação de a Escola do Direito Natural e das Gentes não se baseia na Lei Divina e sim na razão humana, diante disto decorre a notável influencia no século XVIII. Os pensamentos de Hugo Grócio foram de destaque nesta escola. Para os adeptos, a tese Jusnaturalista trata a liberdade como Direito Natural, o qual será o fundamento do Poder Constituinte.

O Direito não se resume ao Direito Positivo. Há um Direito Natural, anterior ao Direito do Estado e superior a este. Deste Direito Natural decorre a liberdade de o homem estabelecer as instituições por que há de ser governado. Destarte, o poder que organiza o Estado, estabelecendo a Constituição, é um poder de direito. (FERREIRA FILHO, 1985, p. 20).

Outrossim, para a corrente jusnaturalista o Poder Constituinte Originário rompe com o ordenamento jurídico precedente, fazendo surgir um novo Estado, uma nova Constituição, no entanto, encontra limites no que tange as normas de ordem jurídica natural, as quais possuem dimensões supra e extraestatal.

\subsection{DOS LIMITES AO PODER CONSTITUINTE ORIGINÁRIO NO ORDENAMENTO PÁTRIO}

A corrente positivista caracteriza o Poder Constituinte Originário como ilimitado, incondicionado e soberano, fazendo surgir um novo ordenamento jurídico e um novo Estado, rompendo com todas as normas precedentes.

Reiteramos que o Supremo Tribunal Federal adotou a teoria positivista no que tange as normas constitucionais, posto que não admite a alegação de inconstitucionalidade das normas expressas no texto constitucional.

Rev. Brasileira de Teoria Constitucional | e-ISSN: 2525-961X | Maranhão | v. 3 | n. 2 | p. 78 - 93 | Jul/Dez. 2017 
O ordenamento pátrio admite para elaboração de uma nova Constituição, o exercício do Poder Constituinte Originário de forma ilimitada.

Os jusnaturalistas entendem que há uma limitação que não decorre de normas escritas, normas postas pelo Estado e sim de limites jurídicos impostos pelo Direito Natural. Como anteriormente visto o Direito Natural antecede ao direito posto e ao próprio homem. Por se tratar de um direito essencial ao indivíduo e a toda a sociedade, sendo a liberdade fundamento do Poder Constituinte, não se pode em um novo ordenamento restringir direito como à vida, valores sociais, intimidade e outros.

Ademais, os direitos naturais não podem ser suprimidos em decorrência da manifestação do Poder Constituinte Originário ao elaborar uma nova Constituição ainda que não haja norma expressa limitando a manifestação daquele aos direitos naturais.

Nos ensinamentos de Gustav Radbruch:

O positivismo, que poderíamos resumir na fórmula lapidar de a lei é a lei, deixou a jurisprudência e o Poder Judiciário alemães inermes contra todas as crueldades e arbitrariedades que, por maiores que tenham sido, foram plasmadas pelas autoridades daquela época sob a forma de lei.

A lei é uma forma de expressão do direito, porém este não se limita ao texto escrito, sendo assim Mendonça (1999, p. 23) aduz:

[...] durante os cinco anos do curso de bacharelado jurídico, o Direito é estudado como sendo a lei, embora não haja sinonímia, não haja equação entre ambos. A lei expressa o Direito, em forma inadequada e pobre, a riqueza da realidade jurídica, mas as dimensões totais do Direito não se encerram apenas nela, expressão limitada, pobre e fugaz de uma realidade rica, permanente e fecunda.

Ribeiro Lopes (1999, p. 107)expõe em seus ensinamentos:

Para os que se filiam a posições jusnaturalistas, que admitem a existência de certos direitos inalienáveis e imprescritíveis, intuídos da própria natureza humana e que precedem a existência do Estado, não resta nenhuma dificuldade na aceitação dos limites ao Poder Constituinte.

Os jusnaturalistas não adotam o posicionamento exposto por Paulo Bonavides (2000, p. 127) o qual aduz que o Poder Constituinte "é o poder que tudo pode". Ressalta-se que tal limitação ao exercício do poder se faz importante posto que não poderia em uma nova ordem constitucional limitar a liberdade do indivíduo ou mesmo afrontar princípios como a dignidade 
da pessoa humana, violando assim o que se denomina de Direito Natural. Todavia esta tese não foi adotada pela doutrina majoritária.

\section{CONCLUSÃO}

O Poder Constituinte originário faz surgir um novo Estado, seja este de forma histórica ou devido ao momento de ruptura com o ordenamento anterior. Sua teoria surgiu no final do século XVIII, ganhando ensejo com o panfleto O que é o Terceiro Estado? de autoria de Emmanuel Sieyès.

Trata-se de um poder que sempre existiu e sempre existirá em todo ordenamento jurídico uma vez que visa estruturar ou reestruturar a Constituição de um Estado, organizando assim a sociedade política.

A titularidade deste poder para Sieyès seria da Nação, identificando-a como base de um elemento da democracia. Para Rousseau, a titularidade é do povo e para o povo e este deve exercer a soberania de forma direita, não sendo cabível a representação. Atualmente predomina, na doutrina, o povo como titular do Poder Constituinte Originário.

O que resta saber é se este Poder Constituinte originário encontra limites ao ser exercido. Para a corrente positivista não haverá limitações uma vez que com a manifestação do poder há uma total ruptura com o ordenamento anterior. A partir do momento em que ocorre essa quebra de ligação com as normas passadas não poderá um novo poder, uma nova Constituição, encontrar barreiras diante de normas ineficazes.

Não existindo normas anteriores quando da ruptura causada pela manifestação do Poder Constituinte originário, não há que se falar em observância de requisitos ou pressupostos formais positivados, não existindo assim, para o positivismo, limitações a elaboração de uma nova Constituição. Portanto, se trata de um poder ilimitado, incondicionado e soberano.

Diferentemente se fará quanto ao jusnaturalismo, posto que para essa corrente o Poder Constituinte originário encontrará limitações materiais ou de conteúdo. Sendo assim, direitos naturais uma vez que não podem ser abolidos, limitam a atuação do Poder Constituinte Originário.

Essencialmente tem-se que o Direito Natural para ser válido independe de norma expressa ou mesmo legislação específica. Pode-se dizer que o direito natural é o núcleo fundamental de um sistema social, portanto, servirá para limitar o direito posto. 
Defendem os jusnaturalistas que não se pode falar, portanto, em supressão do direito natural em uma nova Constituição ou mesmo em uma primeira Constituição. Este direito cria limites ao direito positivo, a norma expressa, para que esta não seja criada forma arbitrária, respeitando os direitos inerentes ao indivíduo.

Todavia, a tese positivista predomina no Direito Pátrio, vigorando a máxima que o Poder Constituinte Originário é ilimitado, incondicionado e soberano, não se sujeitando a qualquer regra de forma ou de fundo. Portanto, as normas constitucionais originárias nunca serão inconstitucionais.

\section{REFERÊNCIAS}

BASTOS, Celso Ribeiro. Dicionário de Direito Constitucional. São Paulo: Saraiva, 1994.

BIDART CAMPOS, German J. Filosifa Del Derecho Constitucional. Buenos Aires: Sociedad Anônima Editora, 1969.

BONAVIDES, Paulo. Curso de Direito Constitucional. $9^{\circ}$ Edição, São Paulo: Malheiros, 2000.

BRONZE, Fernando José. Lições de Introdução ao Direito. Coimbra: Coimbra Editora, 2002.

CANOTILHO, J. J. Gomes. Direito Constitucional. Coimbra: Almedina, 1993.

FERREIRA FILHO. Curso de Direito Constitucional. 27ª ed. São Paulo: Saraiva, 2001.

FERREIRA FILHO, Manoel Gonçalves. O Poder Constituinte. 5a Ed. São Paulo: Saraiva, 2007.

LISOWSKI, Telma Rocha. O Poder Constituinte entre continuidade e ruptura: limites, tradição e transformação. São Paulo. 2013.

MENDONÇA, Jacy de Souza. O Curso de Filosofia do Direito do Professor Armando Câmara. Porto Alegre: Sergio Antonio Fabris Editor, 1999.

MODESTO Paloma Santana. Poder Constituinte Originário. Revista de Direito Constitucional e Ciência Política, vol. 29/96-111, outubro-dezembro de 1999.

MONTEIRO, Marli. Positivismo e direito: a semântica construtiva. 2010. 92 f. Dissertação (mestrado) - Universidade Estadual Paulista, Faculdade de Filosofia de Marília, 2010. Disponível em: 〈http://hdl.handle.net/11449/91759>. Acesso em 25 set. 2016.

NEVES, Antônio Castanheira. Digesta: escritos acerca do direito, do pensamento jurídico, de sua metodologia e outros. Coimbra Editora, 1995. vol. II. 
OTT, Hugo. Martin Heidegger: A Political Life. New York: Fontana Press, 1992.

PASQUINO, Pasquale. Sieyes et l'Invention de la Constituition em France. Paris: Éditions Odile Jacob, 1998.

PEREZ LUÑO, Antonio-Enrique. Iusnaturalismo y Positivismo Jurídico en la Italia Moderna. 1971.

RADBRUCH, Gustav. Introdução à Filosofia do Direito. Tradução feita pelo Professor Jacy de Souza Mendonça. Disponível em: $<$ http://www.valorjustica.com.br/introducao.pdf $>$. Acesso em 05 set. 2016.

RIBEIRO LOPES, Maurício A. Poder Constituinte Reformador: limites e possibilidades da revisão constitucional brasileira. São Paulo: Revista dos Tribunais. 1999.

SIEYÈS, Emmanuel. Que es el Tercer Estado? Introducción, traducción y notas de Francisco ayala. Madrid: Aguilar, 1973.

TEMER, Michel. Elementos de Direito Constitucional. 18. ed.. São Paulo: Malheiros, 2002. 